\title{
Synthesis and Binding Properties of Novel Cyclodextrin Dimers.
}

\author{
Fokke Venema,a Chantal M. Baselier,a Erik van Dienst, b Blanca H.M. Ruël,b \\ Martinus C. Feiters, ${ }^{a}$ Johan F.J. Engbersen, b David N. Reinhoudt, ${ }^{b}$ \\ and Roeland J.M. Nolte ${ }^{a^{*}}$
}

\author{
a Department of Organic Chemistry, NSR-Center, University of Nijmegen, Toernooiveld, 6525 ED Nijmegen, The Netherlands \\ b Laboratory of Organic Chemistry, University of Twente, P.O. Box 217, 7500 AE Enschede, The Netherlands.
}

\begin{abstract}
The synthesis of three cyclodextrin dimers from the novel building block 3-amino-3-deoxyheptakis( $6-O$-tert-butyldimethylsilyl)- $\beta$-cylodextrin is reported. The cyclodextrins are linked with an amide bond on their secondary sides to an ethylene, octamethylene, or a metal binding bipyridyl group. Complexation studies with the substrate 6-(p-toluidino)-2-naphthalenesulfonic acid are presented and discussed.
\end{abstract}

In the last 15 years a number of cyclodextrin dimers have been prepared to investigate the effect of two covalently linked host molecules on the binding of guest molecules. These dimers can be roughly divided into two groups: cyclodextrins (CD's) that are connected by linking spacers at the primary side ${ }^{1-7}$ and cyclodextrins that are connected through spacers at the secondary side. $3,7,8$ It has been shown that the binding constants of CD-dimers can be very large $\left(K_{b}>10^{10} M^{-1}\right)$ if the substrate is chosen properly. ${ }^{6}$

We are interested in the synthesis of $\mathrm{CD}$-dimers for catalytic purposes by using the spacer to immobilise a catalytically active metal centre and the two cavities for complexation and co-complexation of substrates. To achieve this goal it is important to develop routes that yield substantial amounts of well characterised host molecules which can be modulated without much changes in the synthetic concept. It occurred to us that 3 amino-3-deoxy-heptakis(6- $O$-tert-butyldimethylsilyl)- $\beta$-cylodextrin 5 would be a versatile building block to construct $C D$-dimers. The analogous compound 3 -amino-3-deoxy- $\beta$-cylodextrin has been previously reported ${ }^{10}$ but the disadvantage of this cyclodextrin is that further functionalisation has to occur quantitatively since separation and purification of the product is difficult and scale limiting. In this paper we describe the synthesis of compound 5 which has been used to obtain three novel CD-dimers in good yields. The binding properties of two of the dimers are evaluated.

$\beta$-Cyclodextrin 1 was silylated as previously described ${ }^{9}$ to give compound 2 in $82 \%$ yield. ${ }^{12}$ Purification was achieved using column chromatography. ${ }^{13}$ Deprotonation of compound 2 (which was first dried at $100^{\circ} \mathrm{C}$ and $0.05 \mathrm{~mm} \mathrm{Hg}$ for $5 \mathrm{hr}$ ) with $\mathrm{NaH}$ in refluxing THF, followed by reaction with tosyl chloride gave a mixture of the starting material and the mono- and di-tosylated products, which could be separated by column chromatography. This method yielded monotosylate 3 in $34 \%$ which is slightly better than a previously published procedure. ${ }^{9}$ Compound 3 was converted into the mono-epoxide 4 with sodiumethoxide in refluxing dry ethanol. This epoxide was opened by nucleophilic attack from ammonia on carbon C- 
3 using an anhydrous saturated solution of this reagent in ethanol and a pressure reactor $\left(70^{\circ} \mathrm{C}, 2\right.$ days, $P= \pm 2$ atm.), yielding $83 \%$ of the mono-amino-cyclodextrin 5 after column chromatography. Compound 5 could also be obtained by treating epoxide 4 with $\mathrm{LiN}_{3}$ in refluxing dry ethanol, followed by reduction of the azide group with $\mathrm{Pd} /\left(\mathrm{H}_{2}, 3 \mathrm{~atm}\right.$.)/C (yield $48 \%$ starting from 3 ). However, the first described method provides a shorter route with higher yield and less purification steps. Compound 5 was desilylated with tetrabutylammonium fluoride (TBAF) in refluxing THF yielding 3-amino-3-deoxy- $\beta$-cyclodextrin which had nearly identical physical and spectroscopic data 14 as the compound reported in the literature.

The cyclodextrin dimers were obtained by reaction of compound 5 with the 4-nitrophenyl esters (or the $\mathrm{N}$ hydroxysuccinimide esters in the case of 6c) of the appropriate dicarboxylic acids, in refluxing THF. Purification by column chromatography yielded $6 a$ and $6 \mathrm{~b}$ in $76 \%$ and $6 \mathrm{c}$ in $47 \%$. Desilylation of the products was achieved with TBAF in refluxing THF (reaction time $8 \mathrm{hr}$ ). After evaporation of the solvent the compounds were dissolved in a small amount of water and precipitated by addition of ethanol. Repeating this procedure twice gave 7a, $b$ and $\mathrm{c}$ in good yields $(95,88$ and $67 \%)$. The dimers gave ${ }^{1} \mathrm{H}-{ }^{13} \mathrm{C}$-NMR spectra, and elemental analysis as expected. 15

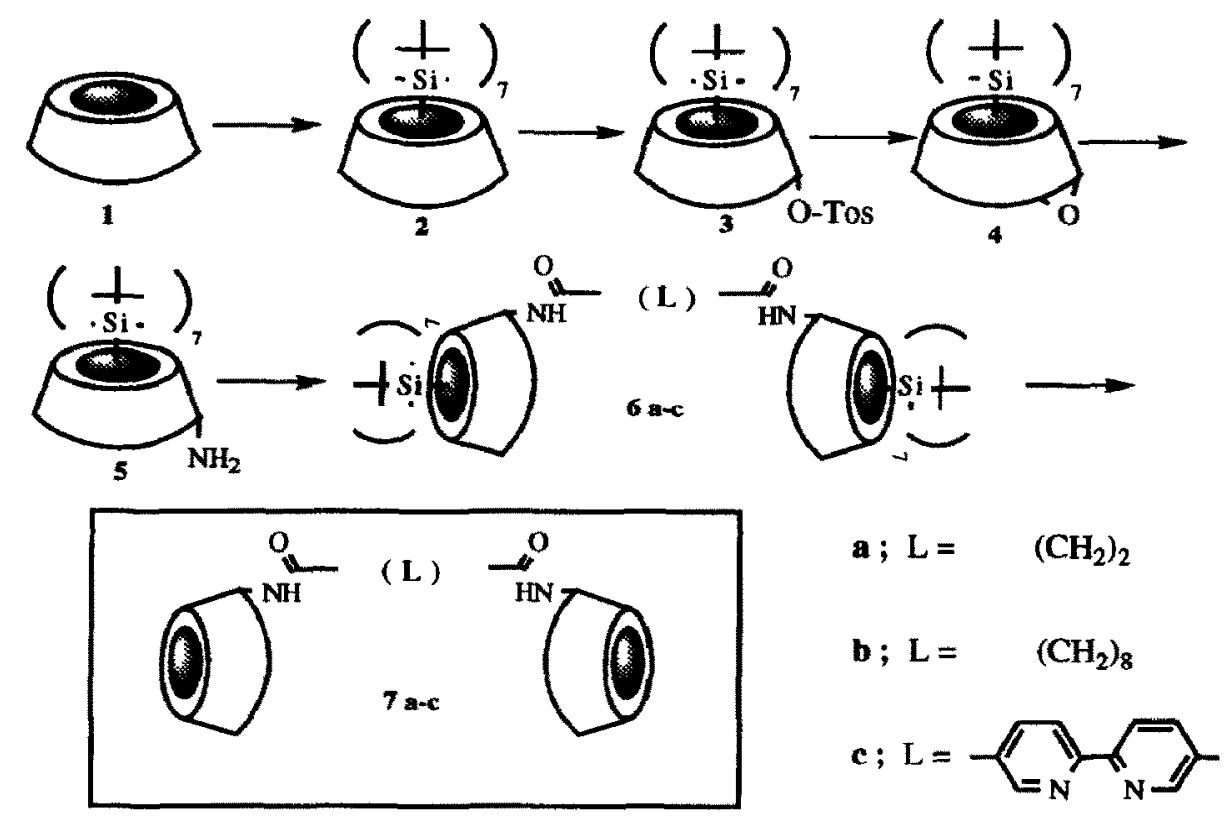

The binding properties of compounds $7 \mathbf{a}$ and $\mathbf{b}$ were studied by fluorescence spectroscopy. As a guest molecule 6-(p-toluidino)-2-naphthalenesulfonic acid (TNS) was used. This probe is water-soluble and barely fluorescent in aqueous solutions but displays strong fluorescence in a hydrophobic environment. TNS in aqueous solutions is known to form 1:1 and 2:1 host:guest complexes with $\beta$-cyclodextrin ${ }^{8}$ and $1: 1$ complexes with cyclodextrin dimers 16 as depicted below. 

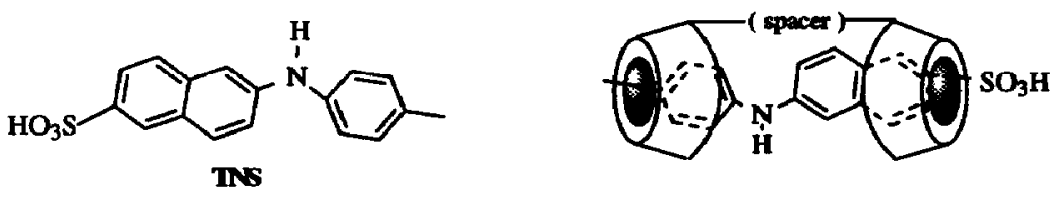

Fluorescence experiments were performed in $0.1 \mathrm{M}$ phosphate buffer $(\mathrm{pH}=7.0$ ). The fluorescence enhancement of TNS $\left(1.10^{-5} \mathrm{M}^{-1}\right)$ on addition of various amounts of CD-dimer $\left(5.10^{-6}-2.10^{-4} \mathrm{M}^{-1}\right)$ was followed at the emission maximum (440 and $436 \mathrm{~nm}$ for $7 \mathrm{a}$ and $\mathbf{7 b}$ respectively, excitation wavelength 322 $\mathrm{nm}$ ). Both dimers caused a considerably larger increase in fluorescence intensity $I_{F}$ ) than compound 1 at equal concentrations of CD-moieties. Double reciprocal plots of the titration data gave straight lines (Figure 1), indicating that the dimer and TNS form 1:1 complexes. This was confirmed by the continuous variation plots, ${ }^{8}$ shown in Figure 2, which for both $7 a$ and $b$ displayed a maximum at 0.50 .

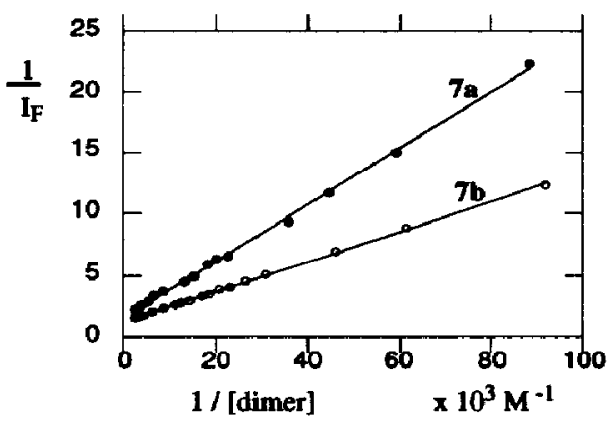

Figure 1: Titration experiments of compounds $7 \mathbf{a}$ and $7 \mathrm{~b}$ with TNS. ( [TNS $]=1 \cdot 10^{-5} \mathrm{M}^{-1}$ )

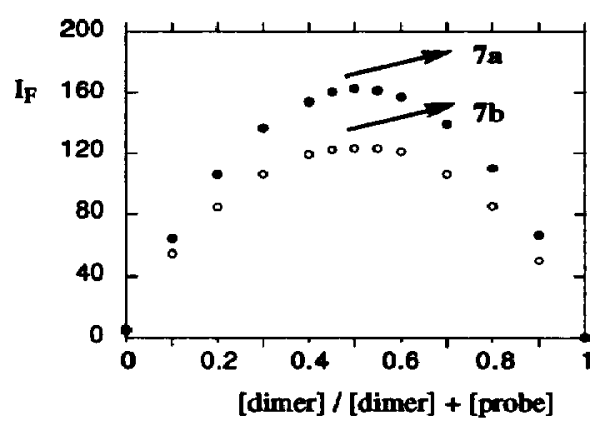

Figure 2 : Continuous variation plots for $7 \mathrm{a}$ and $7 \mathrm{~b}$ ( [TNS $]+[$ dimer $]=2.10^{-5} \mathrm{M}^{-1}$ )

From the slopes and intercepts of the curves in Figure 1 the binding constants can be calculated. They amount to $K_{b}=(10.5 \pm 0.2) .10^{3} \mathrm{M}^{-1}$ and $K_{b}=(6.7 \pm 0.3) .10^{3} \mathrm{M}^{-1}$ for $7 \mathrm{a}$ and $7 \mathrm{~b}$ respectively. These values indicate that a short spacer group results in better binding of the substrate, as was predicted from inspection of CPK-models. The binding constants are in the same order of magnitude $\left(K_{b}=8.10^{3}-7.10^{4} \mathrm{M}^{-1}\right)$ as those reported in the literature for CD-moieties linked at their secondary sides via ester bonds ${ }^{16}$ or for CD's linked via sulfur bonds ${ }^{17}$ at their primary sides. We may therefore conclude that there is not a large difference in binding properties when amide bonds are used instead of ester bonds for connecting the secondary sides.

The emission maximum $\left(\lambda F_{\max }\right)$ of TNS provides information on the polarity of the environment of the probe. The $\lambda F_{\max }$ values of the dimers $7 \mathrm{a}$ and $7 \mathrm{~b}$ are similar to values reported in the literature ${ }^{16}$ for the 2:1 complex between TNS and $\beta$-cyclodextrin indicating that the TNS molecule in both cases is bound to two CD's. The larger blue shift of $\lambda F_{\max }$ observed for compound $7 b\left(\lambda F_{\max }=436 \mathrm{~nm}\right)$ as compared to $7 \mathrm{a}$ $\left(\lambda F_{\max }=440 \mathrm{~nm}\right)$ suggests that the longer alkyl chain results in a more apolar,environment of the probe.

The bipyridyl ligand in dimer $7 \mathrm{c}$ can be used to bind different metal centers. For example, we have introduced a rhodium metal center by treating $7 \mathrm{c}$ with $\left[\mathrm{Cp}^{*} \mathrm{RhCl}_{2}\right]_{2}$ in DMF resulting in compound 8 in $95 \%$ yield. Complexes of type $\mathbf{8}$ are currently tested as shape selective catalysts. 


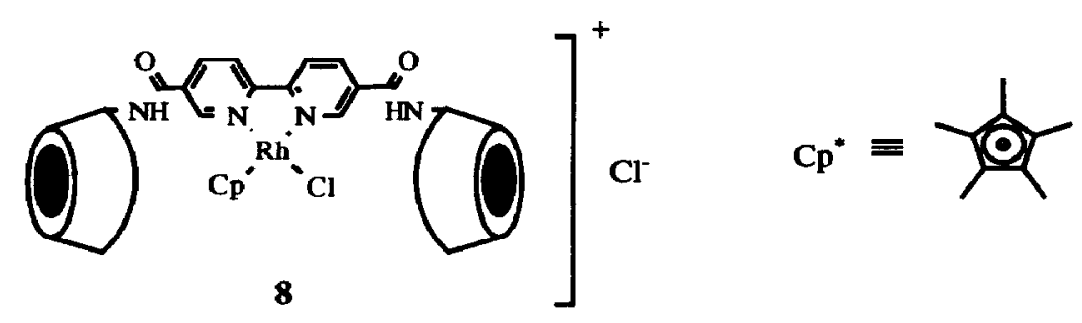

\section{References and Notes:}

1. K. Fujita, S. Ejima, and T. Imoto, J. Chem. Soc. Chem. Commun., 1277 (1984).

2. K. Fujita, S. Ejima, and T. Imoto, Chem. Lett., 11 (1985).

3. R. Breslow, N. Greenspoon, T. Guo, and R. Zarzycki, J. Am. Chem. Soc., 111, 8296 (1989).

4. R. Breslow, and B. Zhang, J. Am. Chem. Soc., 115, 9353 (1993).

5. J.H. Coates, G.J. Easton, S.J. van Eyk, S.F. Lincoln, B.L. May, C.B. Whalland, and M.L. Williams, J. Chem. Soc. Perkin Trans., 1, 2619 (1990).

6. R. Breslow, S. Chung, J. Am. Chem. Soc., 112,9659 (1990).

7. I. Tabushi, Y. Kuroda, and K. Shimokawa, J. Am. Chem. Soc., 101, 1614 (1979).

8. A. Harada, M. Furue, and S. I. Nozakura, Macromolecules, 10, 676 (1977).

9. M.J. Pregel and E. Buncel, Can. J. Chem., 69, 130 (1991).

10. T. Murakami, K. Harata, and S. Morimoto, Chem. Lett., 553 (1988).

11. P. Zhang, C. Ling, A.W. Coleman, H. Parrot-Lopez, and H. Galons, Tetrahedron Lett., 32,2769 (1991).

12. Repeated crystallisation from $\mathrm{CHCl}_{3} / \mathrm{MeOH}$ as recommended in the literature ${ }^{11}$ did not yield a TLC pure product.

13. Purification of all the silylated compounds was achieved by flash chromatography on silicagel (particle size $<0.063 \mathrm{~nm}$ ) with the following eluent systems : ethyl acetate-ethanol-water, 50:2:1 v/v, for compounds $3,6 a, 6 b$, and $6 c$ and ethyl acetate-ethanol-water, $25: 2: 1 \mathrm{v} / \mathrm{v}$, followed by $16: 2: 1 \mathrm{v} / \mathrm{v}$, for compound 5 ( $0.5 \%$ triethylamine was added during packing of the column ).

14. We found a signal for one proton at $4.19 \mathrm{ppm}$ instead of two protons as reported by Murakami. 10

$5 \mathrm{a}^{1} \mathrm{H}-\mathrm{NMR}\left(\mathrm{D}_{2} \mathrm{O}\right) \delta: 5.1(\mathrm{~m}, 2 \mathrm{H}), 5.0-4.96(\mathrm{~m}, 4 \mathrm{H}), 4.79-4.77$ (d,J=6.7 Hz,1 H), 4.19 (q, J=3.8 $\mathrm{Hz}, 1 \mathrm{H}$ ), 3.96-3.78 en 3.64-3.53 (2 $\mathrm{x} \mathrm{m}, \pm 40 \mathrm{H}$ ), 3.74-3.70 (dd, J=4.1 Hz and $\mathrm{J}=12.3 \mathrm{~Hz}$ ), 2.99-2.96 (dd, $J=3.7 \mathrm{~Hz}$ and $\mathrm{J}=9.8 \mathrm{~Hz}, 1 \mathrm{H}),{ }^{13} \mathrm{C}-\mathrm{NMR}\left(\mathrm{D}_{2} \mathrm{O}\right) \delta: 106.0,104-103.5,83.5-83.0,82.2,81.3,78.3$, 75.6-73.7, 62.8, 62.1, 54.6. Anal. calcd for 5a.6 H2O : C, 40.61\%; H, 6.74\%; N, 1.13\%. Found: C, $40.90 \% ; \mathrm{H}, 6.75 \% ; \mathrm{N}, 1.20 \%$.

15. NMR-spectra of 5 and its derivatives are very complex because one glucose-unit is converted into an altrose-unit if an epoxide like 4 is opened with a nucleophile. 10,18 This results in a disturbance of the $C_{7}$ symmetry.

7a $1 \mathrm{H}-\mathrm{NMR}\left(\mathrm{D}_{2} \mathrm{O}\right) \delta: 5.09$ (d,J=3.8 Hz, 1H), 5.03-4.96 (m, 1H), 4.90 (d, J=6.5 Hz), 4.21-4.15 $(\mathrm{m}, 4 \mathrm{H}), \quad 3.96-3.75$ and 3.66-3.52 $(2 \times \mathrm{m}, 84 \mathrm{H}), 2.57(\mathrm{~m}, 4 \mathrm{H}),{ }^{13} \mathrm{C}-\mathrm{NMR}\left(\mathrm{D}_{2} \mathrm{O}\right) \mathrm{d}: 176.1,105.1-$ $102.4,82.3-81.2,74.4-71.1,61.6,61.0,59.4,52.2,32.3$. Anal. calcd for $7 \mathbf{a} .15 \mathrm{H}_{2} \mathrm{O}: \mathrm{C}, 40.34 \%$; H, 6.69\%; N, 1.07\%. Found: C, 39.92\%; H, 6.52\%; N, 1.07\%. FAB-MS (glycerol): $2349.9(\mathrm{M}+1)$.

7b ${ }^{1} \mathrm{H}-\mathrm{NMR}$ (DMSO-d6) $\delta: 5.10$ and 5.02-4.90 (d and $\left.\mathrm{m}, 14 \mathrm{H}\right), 4.09(\mathrm{~m}, 4 \mathrm{H}), 3.94-3.71$ and 3.66$3.35(2 \times \mathrm{m}, 84 \mathrm{H}), 2.06(\mathrm{t}, 4 \mathrm{H}), 1.47(\mathrm{~m}, 4 \mathrm{H}), 1.23(\mathrm{~m}, 8 \mathrm{H})$. Anal. calcd for $7 \mathrm{~b} .7 \mathrm{H}_{2} \mathrm{O}: \mathrm{C}, 44.10 \%$; H, 6.69\%; N, 1.09\%. Found: C, 44.01\%; H, 6.91\%; N, 1.17\%. FAB-MS (glycerol): 2430.5 (M-2).

$7 \mathrm{c}^{1} \mathrm{H}-\mathrm{NMR}\left(\mathrm{D}_{2} \mathrm{O}\right) \delta: 8.90(\mathrm{~s}, 2 \mathrm{H}), 8.24(\mathrm{~s}, 2 \mathrm{H}), 8.13(\mathrm{~s}, 2 \mathrm{H}), 5.08-4.98(\mathrm{~m}, 14 \mathrm{H}), 4.50(\mathrm{~m}, 2 \mathrm{H})$, 4.21-3.49 (m, 82H). 13C-NMR ( $\left.{ }_{2} \mathrm{O}\right) \mathrm{d}: 169.0,157.7,149.5,138.5,131.4,123.3,105.0,103.2-$ 102.5, 82.4-81.4, 74.4-71.1, 61.5, 61.1, 53.0. Anal. calcd for 7c. $14 \mathrm{H}_{2} \mathrm{O}: \mathrm{C}, 41.92 \% ; \mathrm{H}, 6.27 \%$; N, $1.84 \%$. Found: C, $41.99 \% ; \mathrm{H}, 6.49 \% ; \mathrm{N}, 1.89 \%$. FAB-MS (nitrobenzyl alcohol): $2477(\mathrm{M}+1)$.

16. A. Harada, M. Furue, and S. I. Nozakura, Polymer J., 12, 29 (1980).

17. R.C. Petter, C.T. Sikorski, and D.H. Waldeck, J. Am. Chem. Soc., 1 13, 2325 (1991).

18. R. Breslow and A.W. Czarnik, J. Am. Chem. Soc., 105, 1390 (1983). 